\title{
Actualización en el manejo de las Mastitis Infecciosas durante la Lactancia Materna
}

\author{
Rocío Vayas Abascal ${ }^{a}$, Luis Carrera Romero ${ }^{b}$
}

\author{
${ }^{a}$ Médico de Familia, \\ Gerencia Atención Primaria, \\ Servicio Cántabro de Salud. \\ ${ }^{b}$ Enfermero, Hospital \\ Universitario Marqués \\ de Valdecilla, Santander \\ (Cantabria).
}

Correspondencia: Rocío Vayas Abascal, Ctra. Trasculina $n^{\circ} 11$, 39720-Riotuerto, Cantabria, (España). Correo electrónico: rocio.vayas@hotmail.com.

Recibido el 19 de agosto de 2011.

Aceptado para su publicación el 31 de agosto de 2011.

\section{RESUMEN}

La interrupción precoz de la lactancia tiene un origen multifactorial, pero dentro de las causas médicas es la mastitis el primer motivo de abandono prematuro e indeseado de la lactancia materna.

El objetivo de este trabajo ha sido realizar una revisión actualizada acerca de la etiología, diagnóstico y manejo clínico-terapéutico de esta enfermedad.

Hemos constatado la escasez de estudios acerca de la microbiología de la leche humana y una falta de ensayos controlados aleatorizados para evaluar el tratamiento eficaz de la enfermedad. En la práctica clínica habitual el diagnóstico y el tratamiento de la mastitis no se sustentan sobre una base científica, lo que conduce a un infradiagnóstico y frecuentemente a un manejo incorrecto que puede acarrear consecuencias relevantes, como el abandono de la lactancia o complicaciones como el absceso mamario o la septicemia. El diagnóstico sigue basándose en la inspección visual de la mama, siendo excepcional la realización de cultivos de leche materna. El tratamiento debería basarse en una extracción efectiva de la leche, sin interrumpir la lactancia, medicación analgésica/antiinflamatoria y antibióticos usados racionalmente. Sin embargo, el tratamiento habitualmente se pauta de forma empírica, siendo el factor que más influye en su elección la preferencia del médico sin pruebas científicas que sustenten la decisión.

La conclusión principal de la revisión realizada es que el cultivo de la leche es una herramienta objetiva fundamental, que debería solicitarse en toda mujer lactante con dolor mamario. El cultivo facilita un diagnóstico correcto de la mastitis, nos permite conocer su etiología y es clave para instaurar un tratamiento adecuado basado en la sensibilidad a los antibióticos del agente causal. Palabras clave. Mastitis, Lactancia Materna, Análisis Microbiológico, Tratamiento.

\section{ABSTRACT}

Update on management of infectious mastitis during the breastfeeding period.

Premature termination of breastfeeding is of mulitfactorial origin, but mastitis is the most important medical reason for early, unwanted weaning. The current study is an updated review of etiology, diagnosis and therapeutics of this disease.

We found few studies on the microbiology of human milk and a lack of randomized, controlled trials evaluating effective treatment of mastitis. In routine clinical practice, diagnosis and treatment of this disease are not based on scientific evidence, leading to underdiagnosis and frequent therapeutic mismanagement, with harmful consequences: cessation of breastfeeding, breast abscess or sepsis. Diagnosis of mastitis continues to be based on visual inspection of the breast and breastmilk cultures are rarely performed. Treatment should be based on effective extraction of the milk, with continued breastfeeding, analgesic/anti-inflammatory drugs and rational use of antibiotics. However, the drug regimen is usually empirically chosen, based on physician's preference and without scientific evidence to support the decision.

The main conclusion of our review is that breastmilk culture is an essential diagnostic tool that should be used for all breastfeeding women with breast pain. It facilitates correct diagnosis of mastitis, its etiology and is the key to establishing proper treatment based on antibiotic sensitivity of the causative agent.

Key words. Mastitis, Breast Feeding, Microbiological Analysis. 


\section{INTRODUCCIÓN}

En los últimos años hemos asistido a una progresiva defensa y apoyo de la lactancia materna (LM). La OMS ha recomendado la lactancia materna exclusiva hasta los 6 meses y mantener la lactancia junto con la alimentación complementaria dos años o más. En España, sin embargo, la duración media de la lactancia sigue siendo corta, produciéndose un abandono muy alto en las primeras semanas, por lo que el número de madres que llegan a los 6 meses con LM exclusiva es bajo. Según la última Encuesta Nacional de Salud (2006), la prevalencia de la lactancia materna en España a las 6 semanas del parto es del $68,4 \%$ (lactancia mixta 2,27\%), a los 3 meses del $52,48 \%$ (mixta 10,83\%) y a los 6 meses cae hasta un $24,72 \%$ (mixta $14,03 \%)^{1}$.

Sería arduo analizar las causas del abandono precoz de la lactancia en nuestro medio, y de hecho son escasos los estudios que las analizan. Está claro que la incorporación de la mujer al trabajo y la falta de información y apoyo juegan un papel fundamental en la duración de la lactancia. Pero dentro de las causas médicas, es la mastitis la principal causa de destete precoz y sobre todo indeseado ${ }^{2}$.

Tradicionalmente la mastitis se ha definido como una afección inflamatoria del pecho, la cual puede acompañarse o no de infección ${ }^{3}$. En la práctica dado que la mayoría de mastitis no infecciosas pasan con la evolución a convertirse en infecciosas muchos autores definen directamente la mastitis como un proceso infeccioso de la glándula mamaria ${ }^{4}$.

La incidencia observada de mastitis varía del 3 al $33 \%$ de las mujeres en periodo de lactancia, pero habitualmente es menor del $10 \%$ en los estudios realizados. Es importante tener en cuenta que la mayoría de los estudios tienen limitaciones metodológicas importantes y no hay estudios de cohortes prospectivos grandes.

La mayoría de estudios señalan que entre el $74 \%$ y el $95 \%$ de los casos ocurren en las primeras 12 semanas. Sin embargo, puede ocurrir en cualquier momento de la lactancia, incluso en el segundo año $0^{2,3}$.

\section{ETIOLOGÍA}

Los cuadros de ingurgitación y de obstrucción de un conducto lácteo, no tratados o con tratamiento inadecuado, así como las grietas en el pezón se han considerado hasta ahora los principales factores predisponentes a la mastitis 5 . Pero si tenemos en cuenta que las bacterias implicadas en las mastitis tienen capacidad por sí solas para provocar la obstrucción de conductos y/o grietas, se comienza a considerar a tales problemas no como factores predisponentes sino como manifestaciones de la propia mastitis.

A día de hoy, y en contraste con los conocimientos veterinarios sobre la flora presente en la leche de vacas, ovejas y cabras, los estudios sobre la microbiología de la leche humana son muy escasos. Aparte de los evidentes intereses económicos de la leche animal, esta situación ha sido propiciada por la idea errónea, mantenida hasta hace pocos años, de que la leche humana era estéril.

Las últimas investigaciones indican que en las mastitis se produce una disbiosis de la flora bacteriana fisiológica de la mama, con un aumento notable y rápido de la concentración de los agentes causales de la enfermedad y la progresiva desaparición del resto de las bacterias "fisiológicas" de la leche (lactobacilos, lactococos, enterococos, bifidobacterias, etc.) mediante procesos de exclusión competitiva.

Los staphylococcus son las bacterias causantes de hasta el $75 \%$ de las mastitis infecciosas. Dentro de ellos, los estafilococos coagulasa negativos, especialmente el s. epidermidis, probablemente están implicados en la mayoría de las mastitis. Este hecho está comprobado en mastitis animales, pero en el caso de la leche humana muchos laboratorios consideran al s. epidermidis como una bacteria saprófita, incluso cuando constituye un monocultivo y su concentración es superior a 10\% $\mathrm{ml}$. Contradictoriamente se acepta sin ningún lugar a duda que el $\mathrm{s}$. epidermidis está asociado a las infecciones por uso de catéteres ${ }^{2,6}$.

Clásicamente se ha asociado el s. aureus a la producción de mastitis, a diferencia de lo que ocurre con s. epidermidis cuyo papel en la etiología de esta infección se podría haber infravalorado debido a que los procedimientos clásicos para identificación de estafilococos no son adecuados para la diferenciación entre estas dos especies.

S. aureus se considera responsable de las mastitis con síntomas evidentes "de libro", y está comúnmente asociado a la formación de abcesos ${ }^{7}$. 
El siguiente grupo bacteriano implicado en la etiología de las mastitis humanas es el de los streptococcus, hallados en un $10-15 \%$ de casos, sólos o asociados a staphylococcus. Clásicamente se pensaba que la especie más frecuente era el s. agalactie, pero estudios más recientes indican que en mastitis humanas son en realidad más frecuentes s. mitis, s. salivaris e incluso s. pneumonie.

Menos comúnmente $(<3 \%)$ pueden estar implicadas corinebacterias o enterobacterias, como e. coli o klebsiella pneumonie. Raramente mycobacterium tuberculosis podría causar mastitis.

Las levaduras son otra causa poco frecuente de mastitis $(<0,5 \%)$, a pesar de lo cual está aun muy extendida la práctica de diagnosticar y tratar mastitis presuntamente candidiásicas, basándose sólo en la inspección visual de la mama, sin llevar a cabo ningún tipo de examen microbiológico.

En cerca de 4.000 muestras analizadas por el equipo de investigación del Departamento de Nutrición, Bromatología y Tecnología de los Alimentos de la Universidad Complutense de Madrid, dirigido por Juan Miguel Rodríguez Gómez, solamente se han hallado 4 casos de mastitis por levaduras formando un monocultivo en una concentración elevada. $Y$ es más, no fueron c. albicans sino levaduras pertenecientes a especies como cándida parapsilopsis o saccharomyces cerevisiae.

Una posible hipótesis de por qué está tan extendida en la práctica clínica la idea de la cándida como causa de mastitis puede ser el hecho de que en un $5-6 \%$ de casos coexisten una mastitis estafilocócica en la madre y una candidiasis oral en su hijo. Pero si se analiza la leche de estas mujeres, se encontrará posiblemente una mínima concentración de levaduras por transferencia de la boca del niño (<100 UFC/ml) y sin embargo una concentración muy superior de estafilococos ${ }^{2,8}$.

\section{DIAGNÓSTICO}

El diagnóstico de mastitis todavía sigue basándose en la mayoría de casos en la inspección visual de la mama. Esta actitud genera un infradiagnóstico franco, ya que aunque clásicamente se ha descrito que la mastitis se manifiesta por dolor intenso y signos inflamatorios (enrojecimiento, tumefacción, induración) y que se acompaña de síntomas generales (fiebre, escalofríos, malestar general, cefaleas, náuseas y vómitos $)^{5}$, sin embargo, en la práctica estas mastitis con una clínica tan florida, sólo aparecen en un $10-15 \%$ de las mujeres afectadas. En la gran mayoría de casos el único síntoma es el dolor intenso, acompañado ocasionalmente de síntomas locales (grietas, zonas induradas), pero sin síntomas sistémicos. Esta ausencia de datos clínicos llamativos y el hecho de que un síntoma subjetivo, como es el dolor, sea la única queja en muchas mujeres favorece que muchos casos queden sin diagnosticar y por tanto sin tratar, generando un sufrimiento innecesario, aumentando el riesgo de complicaciones (absceso mamario, mastitis recurrente, septicemia) y acabando en ocasiones en el abandono innecesario de la lactancia.

Otra idea falsa ampliamente difundida es la unilateralidad de las mastitis, cuando en realidad pueden ser tanto unilaterales como bilaterales, e incluso una mastitis inicialmente unilateral puede derivar en bilateral.

Dicho lo anterior, parece obvio que se debería realizar un análisis microbiológico de la leche de todas las madres lactantes que refieran dolor en el pecho. La recogida de la muestra de leche debe realizarse dentro de las siguientes pautas para evitar errores:

- Se debe recoger inmediatamente antes de una toma.

- Tras lavado de manos con agua caliente y jabón y secado con toalla limpia o toallita de un solo uso.

- La recogida se debe efectuar mediante presión manual. No deben usarse sacaleches, ya que pueden ser una fuente importante de microorganismos ajenos a la glándula mamaria. Por tanto, su presencia puede enmascarar los verdaderos agentes responsables de una mastitis. En general, los microorganismos contaminantes suelen ser enterobacterias, pseudomonas spp. y levaduras, que sin embargo están ausentes o presentes en concentraciones muy bajas en la leche humana.

- Se deben recoger en envases estériles, como los empleados en el análisis de muestras de orina o heces, y usando uno para cada mama.

- El volumen necesario para el cultivo es de 1 $\mathrm{mL}$.

- Las muestras pueden permanecer sin refrigerar un máximo de 1 hora. Si el tiempo de entrega va a ser superior, se pueden mantener en refrigeración a $4^{\circ} \mathrm{C}$ durante un máximo de 12 horas. Si van a pasar más de 12 horas es preferible conservarlas congeladas a una 
temperatura igual o inferior a $-20^{\circ} \mathrm{C}$, sin que se rompa la cadena de frío.

Respecto a la interpretación de los resultados del cultivo, resultan fundamentales las siguientes premisas :

- Los estafilococos coagulasa-negativos (especialmente s. epidermidis) y estreptococos del grupo viridans (especialmente s. mitis y s. salivarius) no deben considerarse como "flora contaminante" o "saprofita", sino como agentes potencialmente causantes de mastitis. Aunque es cierto que en condiciones fisiológicas son bacterias que pueden estar presentes en la leche materna, su concentración en muestras de leche de mujeres sin mastitis recogidas adecuadamente suele oscilar entre 100-300 UFC/mL, con un límite máximo de, aproximadamente, $1.000 \mathrm{UFC} / \mathrm{mL}$. Cualquier valor superior puede ser compatible con una mastitis infecciosa. No obstante, si hay mastitis, el valor suele estar notablemente aumentado (>5.000 UFC/mL).

- S. aureus y corynebacterium spp. no suelen estar presentes en la leche humana en condiciones fisiológicas y pueden provocar mastitis en concentraciones mucho más bajas que las especies antes citadas ( $<500$ UFC/ $\mathrm{mL})^{9}$.

\section{TRATAMIENTO}

Los pilares del tratamiento actualmente deberían ser una extracción efectiva de la leche, continuando con la lactancia, medicación analgésica/antiinflamatoria y antibióticos usados racionalmente.

A pesar de la relevancia de la enfermedad, no hay un consenso en la práctica para el tratamiento de las mastitis y hay una falta evidente de ensayos controlados aleatorizados para evaluar la mejor antibioterapia $^{10}$.

Los errores más frecuentes en el manejo terapéutico son :

- Pautar un antibiótico de forma empírica, habitualmente un betalactámico (cloxacilina, amoxicilina, amoxicilina-ácido clavulánico, mupirocina o eritromicina) o un antifúngico. Un porcentaje cada vez más elevado de cepas implicadas en la mastitis son resistentes a los betalactámicos y como hemos visto previamente las mastitis fúngicas son poco frecuentes. Esta actitud favorece que una mastitis pueda derivar en una infección crónica o recurrente. La actitud más eficaz sería instaurar el tratamiento previo análisis microbiológico que determine el agente causal y su sensibilidad a los antibióticos.

- Indicar la suspensión de la lactancia ante el desconocimiento de los medicamentos compatibles con la lactancia por parte de algunos profesionales. Sigue muy extendida la creencia de que algunos antibióticos eficaces en estos casos, como el sulfametoxazol/trimetoprim o el ciprofloxacino, hacen necesaria la interrupción de la lactancia. Realmente son pocos los principios activos realmente incompatibles con la lactancia (http://www.elactancia.org) ${ }^{11}$.

- Indicar el destete por miedo a efectos negativos en el lactante. Los datos disponibles muestran que la calidad nutritiva y funcional de la leche de una mujer con mastitis es superior a la de la leche artificial. El consumo de leche mastítica no conduce a una infección en el lactante, salvo los casos excepcionales de asociación mastitis estafilocócica-candidiasis oral o dermatitis en nalgas y genitales, que no implican gravedad. Hay que tener en cuenta que el intestino infantil contiene una concentración bacteriana mucho más elevada que la presente en la leche mastítica, por lo que el impacto de un exceso de estafilococos y estreptococos resulta insignificante ${ }^{2}$.

\section{BIBLIOGRAFÍA}

1. Grupo de trabajo CS-IHAN. Centros de Salud IHAN (Iniciativa de Humanización de la Atención al nacimiento y la Lactancia). Una garantía de calidad. Rev Pediatr Aten Primaria. 2009; 11:513-29.

2. Delgado S, Arroyo R, Jiménez E, Fernández L, Rodríguez JM. Mastitis infecciosas durante la lactancia: un problema infravalorado (I) y (II). Acta Pediatr Esp. 2009; 67(2):77-84.

3. OMS. Mastitis: causa y manejo. Ginebra: OMS; 2000.

4. Lawrence RA, Lawrence RM. Breastfeeding. A guide for the medical profesión, $6^{a}$ ed. St Louis: Mosby; 2005.

5. Diaz NM. Retención y mastitis. En: Lactancia materna: guía para profesionales. Monografías de la Asociación Española de Pediatría. Madrid: Ergón; 2004. p. 235-41.

6. Pascual A, Bouza E, Liñares J. Diagnóstico microbiológico de las infecciones asociadas a catéteres intravasculares. [Internet] Procedimientos en Microbiología Clínica. Recomendaciones de la Sociedad Española de Enfermedades Infecciosas y Microbiología Clínica; 2004 [acceso 29 julio de 2010]. Disponible en: http://www.seimc. org/documentos/protocolos/microbiologia/cap15.

7. Stafford I, Hernandez J, Laibl V, Sheffield J, Roberts S, Wendel G. Community-acquired methicillin-resistant Staphylococcus aureus among patients with puerperal mastitis requiring hospitalization. Obstet Gynecol. 2008; 112(3):533-7. 
8. Carmichael AR, Dixon JM. Is lactation mastitis and shooting breast pain experienced by women during lactation caused by Candida albicans? Breast. 2002; 11:88-90.

9. Arroyo R, Mediano P, Martín V, Jiménez E, Delgado S, Fernández $L$, et al. Diagnóstico etiológico de las mastitis infecciosas: propuesta de protocolo para el cultivo de muestras de leche humana. Acta Pediatr Esp. 2011; 69(6):276-81.

10. Shayesteh Jahanfar, Chirk-Jenn Ng, Cheong Lieng Teng. Antibióticos para la mastitis en mujeres que amamantan
(Revision Cochrane traducida). En: Biblioteca Cochrane Plus $2009 \mathrm{~N}^{\circ} 2$ 2. Oxford: Update Software Ltd. Disponible en: http://www.update-software.com. (Traducida de The Cochrane Library, 2009 Issue 1 Art no. CD005458. Chichester, UK: John Wiley \& Sons, Ltd.).

11. Servicio Pediatría Hospital Denia. Web de lactancia materna [Internet]. Alicante [fecha de actualización 26 julio 2011, acceso 11 agosto 2011]. Disponible en http://www.elactancia.org/. 